Review Article

\title{
Circulating tumor cells: historical highlights on preventing the hindrance of progress in this field
}

\begin{abstract}
In 1834, an eponymous giant styled as "King's Professor of the Institutes of Medicine" at the University of Dublin, predicted that the writing of Case Reports of lung tumors would enable practitioners "to arrive at some degree of certainty even in this difficult and obscure branch of thoracic pathology." Accordingly, this review provides - from that year to 1892the chronology of the opinions concerning the circulating tumor cells with special reference to preventing the hindrance of progress in this field.
\end{abstract}

Keywords: tumor, cells, circulating, progress, preventing hindrance
Volume 7 Issue 2 - 2017

\author{
Wilson Onuigbo \\ Department of Pathology, Medical Foundation and Clinic, \\ Nigeria
}

Correspondence: Wilson Onuigbo, Department of Pathology, Medical Foundation and Clinic, 8 Nsukka Lane, Enugu 40000I, Nigeria,Email Wilson.onuigbo@gmail.com

Received: October 10, 2016 | Published: January 17, 2017

\section{Introduction}

Robert Graves, ${ }^{1}$ who was an eponymous giant, became the King's Professor of Medicine at the Dublin University. In 1834, he was moved strongly to portray in capitals the "Conversion of the Whole Right Lung into an Encephaloid or Brain-Like Structure." Indeed, the boldness of the script equalled that of his timely testament as follows:

Rare diseases should not be looked upon as mere matters of curiosity, but should be attentively studied with the view of enabling us to recognize the true nature of similar cases when they again occur. Were the history of diseases, at present reputed to be extremely uncommon, published by all those who meet with them, facts, now apparently single and insulated, would serve as nuclei round which future experience and observation might cluster together similar facts in groups sufficiently numerous to illustrate and explain each other The diagnosis of encephaloid tumors of the lungs was, a few years ago, completely impossible; but I trust that ere long we may be enabled to arrive at some degree of certainty even in this difficult and obscure branch of thoracic pathology. The wish to promote so desirable an object, has induced me to publish the details of the following case, chiefly valuable on account of the accuracy with which the symptoms were observed during life.

\section{Historical texts}

1834-Graves" saw that "the heart was pale, and rather atrophied; its great vessels seemed to run through the substance of the mass which surrounded the bases of the heart, so that only it's lower part was visible."

1842-Stoke ${ }^{2}$ found in his Case 4 that "In the branch of the right pulmonary artery, going to the lobe, there was a small pedunculated medullary tubercle, and another on its external surface." Incidentally, he cited another author thus: "It also was pressed upon the posterior part of the right auricle, so as to burst it inwards, and, in one part, a small tubercle, about the size of a pea, had penetrated; it had also made its way into the cavity of the left auricle, and two tubercles, suspended by narrow peduncles, hung down from the tumour into this cavity."

1855-Wilks ${ }^{3}$ waxed eloquent thus: On opening the pericardium, the cancer was seen protruding itself into that sac. The cancer had not affected any of the cervical or other glands, and all other parts of the body were free from the disease. On removing the heart, the cancer was seen to involve all the great vessels at its base, and, running along these, had pierced the auricles of the organ itself. The superior cava was at first not to be found, being, apparently, destroyed in the malignant growth. By tracing it up, however, from the heart, remains of the anterior wall were found. The posterior wall was quite destroyed. The cancer was closely in contact with the inner surface of the anterior wall of the vessel, and although apparently no space existed between them, still, from the soft nature of the morbid material, it is possible some small quantity of blood might have passed, though this is very improbable. The inferior cava was closely surrounded, but free. The right division of the pulmonary artery was only discovered by making a section of the cancerous mass, and then was found as a mere slit in the midst of it, incapable of transmitting any blood. A cancerous fungoid growth protruded from the posterior wall of the right auricle into its cavity. This was about the size of a large walnut. On the left side, the cancer seemed to have entered the heart by the pulmonary veins. The left branches were quite lost, and in their place a large fungoid tumor projected into the auricle. It was of the size of an egg, and more than half filled the cavity.

1857-Bell ${ }^{4}$ broached the microscopic plane: On a microscopical examination, these tumours were found to consist of a fibrous intercircular stroma, that is, bands of fibres arranged in a circular form, the interstices filled with polyancleated irregular-shaped cells, and small granules, loose nuclei; -in every respect having the appearance of cancer tissue. The smaller and more superficial tubercles were of similar structure, except that the cells were more numerous, and mixed with fibrin and exudation corpuscles; a few fat globules also existed.

1863-Peacock ${ }^{5}$ could perceive similarities: There was a layer of recent lymph on the surface of the heart, with some nodules of carcinoma under the attached pericardium; and similar masses existed beneath the endocardium.

1865-Andrew ${ }^{6}$ drew attention thus: The left innominate vein is all but obliterated, the most contracted portion being occupied by a clot which is firmly adherent to the walls of the vessel, and which appears to have been itself invaded by the disease by direct continuity. The branches of the pulmonary artery supplying the affected lobe are completely obliterated. Heart - Recent acute pericarditis. Projecting 
into the interior of the left auricle from the orifice of the left pulmonary vein, which it completely obstructs, is a small nodulated, buttonshaped tumour.

1868-Powel ${ }^{7}$ was aware of interesting facts: An ovoid elevation, two inches and a half by two, projected from inner surface of left parietal portion of pericardium on a level with left auricle; but between it and the auricle, another rounded nodule projected, about the size of an unshelled walnut; this nodule formed a bulging within the auricle one inch and half by one and a quarter, between the apertures of the pulmonary veins.

1871-Arnott ${ }^{8}$ noted the prevailing theory: No doubt the doctrine of embolism as set forth by Dr Kirkes and amplified by many subsequent observers has gone far to remove from the diffusion of cancer the mystery which formerly enshrounded it, and the great majority of secondary growths may be explained by a transference of cells or fluid from the primary tumour by either the lymph- or blood-channels.

1878-Church ${ }^{9}$ chose his words carefully: Projecting into the left side of the pericardium was a red-looking fungous mass, which had displaced the heart; this mass was a portion of a large tumour which nearly filled the left side of the chest, compressing the lung against the chest walls, and rendering it airless. The tumour partly surrounded the aesophagus, but its walls were not involved in the disease. The tumour had not affected the walls of the chest either by extension into the tissues, or by causing absorption of them. There was no defined line of demarcation between the tumour and the lung which it compressed; the cavity of the left pleura was obliterated everywhere by very firm adhesions; the tumour appeared to have sprung from the root of the lung. The right pleura and lung were healthy.

1884-Moore ${ }^{10}$ mentioned interesting appearances: At the base of the heart and for one third downwards on its anterior surface, and two thirds downwards behind, the visceral layer of the pericardium was infiltrated with a firm, whitish new growth, and this extended over a lesser area of the parietal surface.

1885-Finlay ${ }^{11}$ was brief: A couple of nodules projected slightly under the superior vena cava, elevating the inner coat of the vessel.

1886-West ${ }^{12}$ was perceptive: The pericardium was dotted with small hæmorrhage and the tumour was visible through it and had spread along the pulmonary veins so as to involve the left auricle.

1888-Handford ${ }^{13}$ dwelt with his Case 3 pointedly: One of the large pulmonary veins was found completely embedded in new growth.

1888-Coats ${ }^{14}$ celebrated with a Figure on the role of the lymphatics: There can be no doubt, on the other hand, that the tumour is advancing by the lymphatics. It is not uncommon to meet with appearances, such as those represented in Figure 1, in which the lymphatics around a branch of the pulmonary artery are filled with epithelium having the characters of that of the tumour proper.

1891-Rolleston ${ }^{15}$ remarked thus: The growth had projected into the pericardium to the right of the superior vena cava.

Harris ${ }^{16}$ viewed the picture briefly: The pericardium was studded with new growths in small masses, and was covered with a deposit of blood-stained lymph.

\section{Discussion}

During the third decade of the $19^{\text {th }}$ century, an eponymous giant pointedly drew attention to the need to improve thoracic pathology through the publication of case reports. Throughout the rest of that century, as many as 16 such reports were published. Accordingly, it is well to conclude that, in focusing on their scripts here, it was found that enough materials exhibited highlights on circulating tumor cells as they were perceived by the medical masters of yester years. Clearly, they prevented the hindrance of progress in this field. ${ }^{17,18}$

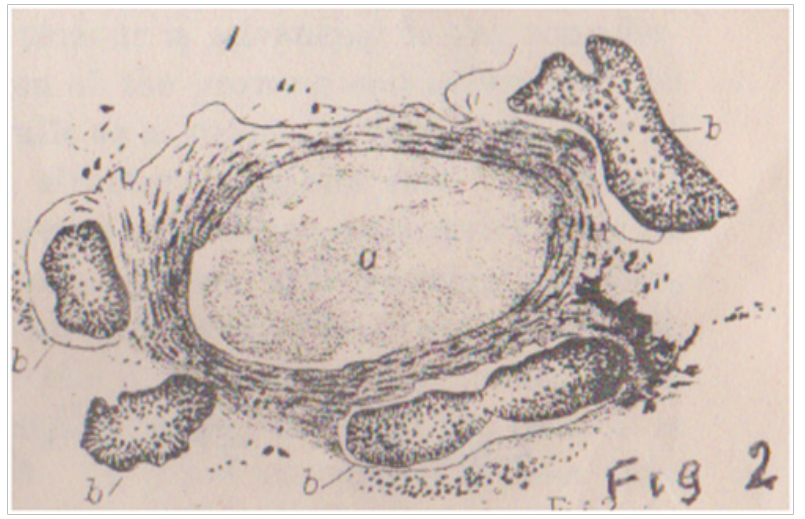

Figure I Advance of cancer in perivascular lymphatics surrounding a blood vessel.

\section{Acknowledgments}

None.

\section{Conflicts of interest}

Author declares there are no conflicts of interest.

\section{References}

1. Graves RJ. Conversion of the whole right lung into an encephaloid or brain-like structure. Dublin J Med Chem Sci. 1834;1834;4(12):321-328.

2. Stokes W. Researches on the pathology and diagnosis of cancers of the lung and mediastinum. Dublin J Med Sci. 1842;21:206-250.

3. Wilks S. Cancerous masses at the base of the heart. Trans Path Soc Lond. 1855;6:113.

4. Bell J. Remarkable cases of malignant encephaloid disease, occurring in Nos. 1 and 2 Medical Wards of the Glasgow Royal Infirmary. Glasgow Med J. 1857;4:419-420.

5. Peacock. Carcinoma of left lung, with secondary deposits in heart, kidneys, supra renal capsules, and intestines; and recent pericarditis. Trans Path Soc Lond. 1863;14:41.

6. Andrew J. Primary cancer of the left lung and of the mediastinal glands Trans Path Soc Lond. 1865;16:51-52.

7. Powel RD. Case of cancer of the lung and bronchial glands, liver, and pancreas. Trans Path Soc Lond. 1868;19:75-76.

8. Arnnot H. On the therapeutical importance of recent views of the nature and structure of cancer. St Thomas's Hosp Repts. 1878;2:108.

9. Church WS. A case of intra-thoracic tumour. St. Barts Hosp Repts. $1878 ; 14: 241-254$

10. Moore N. New growths in the mediastinum. Trans Path Soc Lond. $1884 ; 35: 372-374$.

11. Finlay. Case of lymphosarcoma of left lung with great displacement of the heart-Autopsy. Med Times. 1885;145-146.

12. West S. Cases of mediastinal tumour. Trans Path Soc Lond. $1888 ; 37: 141-142$ 
13. Handford H. Two cases of mediastinal cancer. Trans Path Soc Lond. 1888;39:48-53.

14. Coats J. Multiple tumours, many of these cystic, in the lung, brain, the primary tumour probably in the lung. Trans Path Soc Lond. 1888;39:326-336

15. Rolleston HD. Mediastinal carcinoma secondary to scirrhus of the pancreas. Trans Path Soc Lond. 1891;42:320.
16. Harris VD. Intra-thoracic growths. St Barts Hosp Repts. 1892;28:83.

17. Onuigbo WIB. Some nineteenth century ideas on links between tuberculous and cancerous diseases of the lung. BrJDis Chest. $1975 ; 69: 207-210$

18. Onuigbo WIB. The plant kingdom featured significantly in the history of cancer. Med \& Aromatic Plants. 2016;:S3:1-4. 